\title{
Self-Esteem, Self-Efficacy and Deviant Behaviour of Young People in Hong Kong
}

\author{
T. Wing Lo, Christopher H. K. Cheng, Dennis S. W. Wong, Tina L. Rochelle, \\ Sharon I. Kwok \\ Department of Applied Social Studies, City University of Hong Kong, Kowloon, Hong Kong, China. \\ Email: \{sstwl, sshkc, ssswwong, rochelle, sikwok\}@cityu.edu.hk \\ Received November $18^{\text {th }}, 2011$; revised December 20 $0^{\text {th }}, 2011$; accepted December $27^{\text {th }}, 2011$.
}

\begin{abstract}
This study was designed to explore the psychological and social correlates of deviant behaviour in a sample of Hong Kong school students. Findings revealed that their deviant behaviour was significantly and positively correlated with rebelliousness and susceptibility to negative peer influence. While weak direct relationships were found between self-efficacy, self-esteem and deviant behaviour in general, we found "bullying/vandalism", "verbally/physically attacking parents", "lack of motivation to study", and "verbally/physically attacking teachers" had significant effects with "self-esteem and/or self-efficacy". The present study concludes that changing the delinquents' deviant identity is essential; the identity-rebuilding process would strengthen their self-image and prevent them from going astray.
\end{abstract}

Keywords: Delinquency, Deviant Behaviour, Self-Esteem, Self-Efficacy, Hong Kong

\section{Introduction}

In recent years there has been an increase in research into the impact of deviant peer affiliations on adjustment in young people (Fergusson et al., 2007; Goodnight et al., 2006). Research has found that adolescents who affiliate with delinquent peers are at increased risks of involvement in criminal activities (Level \& Chamberlain, 2005), substance use (Claes et al., 2005), and mental health problems (Fergusson et al., 2003). In part, at least, these associations appear to reflect the fact that, through a number of processes, deviant peer affiliations act to increase the risks of behavioural difficulties (Schwartz et al., 2006; Fergusson et al., 2007). The issue of deviant behaviour among young people has become increasingly common in Hong Kong of late and has aroused the concerns of the Hong Kong Government, education sector, social workers and the police force.

\section{Peers and Unruly Behaviour}

Adolescence is known as a time of unpredictable behaviour, emotional upheavals and high rebelliousness. Adolescents at this life stage are striving for self-development and independence, developing their self-image, and learning and experimenting with the behavioural norms of adult society in order to gain trust and acceptance from others, particularly their peers (Allen et al., 2005). School and family are places for adolescent growth in which, psychologically, adolescents are developing and attempting to demonstrate signs of maturity by building their selfimage and learning appropriate social behaviour.

Research suggests that as adolescents leave their parents in order to develop an independent lifestyle, peer acceptance is of the utmost importance (Chen et al., 2005). Adolescents may be faced with numerous setbacks in the process of establishing their self-identity and integrating into the community. From this perspective, rebellious behaviour may be viewed as a sign of growth and independence. However, if assurance and acceptance are not gained within the traditional groups (e.g. school, community, and family), values and self-concepts may not be properly developed. This may lead adolescents to seek life satisfaction and fulfil their psychological needs through their peer group. In this case, the social appropriateness of group interacttions may be overlooked by adolescents in order to feel accepted within the peer group. Such subtle relationships between deviant behaviour and self-concepts have been reported (e.g. Kaplan, 1975; DuBois \& Silverthorn, 2004; Bartlett et al., 2006).

Research has shown that students with less favourable school performance are likely to affiliate with one another for group support (Wentzel, 1994, 2004). Once becoming labelled as a poor performer, prosocial behaviour may be exhibited when faced with the dilemma of choosing to perform well at school and receive praise from teachers or to perform badly but be accepted by peers (Wentzel, 1994). Though they may exhibit delinquent behaviour in order to gain acceptance from their peers, this does not necessarily apply to all under-performing students. Many students respond positively to setbacks and failures encountered, however some are prone to display more deviant behaviour. Psychological factors, such as self-esteem and self-efficacy, have been shown to be equally as important as social factors in contributing to the cause of deviant behaviour (Becker \& Luthar, 2007; DuBois \& Silverthorn, 2004; Schwartz et al., 2006). Though peer acceptance is particularly important to adolescents, individual differences in ways of maintaining self-discipline amongst peer influence may still exist.

\section{Gender Differences, Self-Concepts and Delinquency}

Recent research has found gender differences in delinquent behaviour (Kim \& Kim, 2005; van Lier et al., 2005). Carroll et al. (1999) found gender differences in reputational profiles, with males perceiving themselves as tougher, more popular, and more of a leader than their female counterparts, who wished to be liked, seeking affection and affiliation. This ties-in with both physical and self-presentation goals set by males, and demonstrates the importance to males at a young age of social status within the peer group. Lau and Leung (1992) suggested in their study that poor relation with school had a more negative effect on the self-concept of girls than boys, and a more negative impact on the delinquency of boys. While good relations with pa- 
rents were found to have a particularly positive effect on the self-concept of boys.

Rigby and Cox (1996), studying factors associated with delinquent behaviour of adolescent school children, found that girls generally reported less delinquent behaviour than boys. They observed that girls with low levels of self-esteem were associated with reported bullying behaviour. However, results also demonstrated that comparatively high levels of reported engagement in peer bullying and relatively low self-esteem were each independently and significantly associated with the measure of delinquent behaviour in both boys and girls.

\section{Self-Esteem, Self-Efficacy and Unruly Behaviour}

It has been acknowledged that having positive self-efficacy and self-esteem is good for well-being (Katja et al., 2002; Karatzias et al., 2006). Psychologists generally regard having a strong sense of self-esteem as a sign of self-understanding and self-acceptance, which allows individuals to view themselves and others equally, achieving one's self-integration and developing one's potential effectively, as well as having a higher expectation for self-efficacy (Tabassam \& Grainger, 2002). There are a number of ways in which young people can benefit from positive selfconcepts. Respect can be gained from surrounding people (family, teachers, peers), which can prevent youth from developing a sense of low self-esteem. This also allows them to be able to face challenges and failures assertively. Secondly, it also allows them to have confidence in developing friendships and to maintain positive relationships with family members and teachers. Research on the relationship between self-concept and youth development has found a positive correlation between high self-esteem and assertive behaviour that can include having a strong sense of self-discipline and good work performance etc. (e.g. Levy, 1997; Donnellan et al., 2005).

Sociologists and psychologists have long considered self-esteem to be an important cause and consequence of social behaviour (Mason, 2001). Kaplan (1975) observed that deviant behaviour may be an adaptation and self-protection against self-derogation. If a sense of self-esteem and positive self-evaluation cannot be gained through socially acceptable methods, motivation for behaving in such a (positive) way will gradually decline. Instead, one may try to gain self-esteem and attention through other means that may include deviant behaviour. Thus, having a low sense of selfesteem has often been regarded as a motivation for deviant behaviour.

It is not the deviant behaviour itself, but rather the acceptance and recognition gained from deviant peers after committing an act of deviance that enhances adolescent's self-esteem (Goodnight et al., 2006; Becker \& Luthar, 2007). Delinquents' sense of self-enhancement and protection can ultimately be gained by strengthening the psychological bonding with other delinquents when they engage in similar behaviour. Therefore, there is not necessarily a direct relationship between unruly behaviour and self-esteem, which can be enhanced through "delinquent association" (Sung \& Thornberry, 1998).

There is evidence supporting the correlation between negative self-esteem and unruly behaviour (Kaplan \& Lin, 2000, 2005). Mason (2001) discovered that boys with low self-esteem could enhance their self-esteem after engaging in unruly behaviour, however, it was observed that such an effect did not occur in boys with high self-esteem. Levy's findings (1997) support Kaplan's theory of self-concept and unruly behaviour. By using multiple self-perception measurements, Levy discovered that selfacceptance (particularly moral self-perception) of severe delin- quents was significantly lower than that of other individuals

Research in Hong Kong has been conducted looking into the possible contributing factors of these problems (Cheung, 1993; Cheung \& Ng, 1988; Li \& Lo, 2006; Lo, 1984; Wong \& Cheng, 2000; Wong \& Leung, 2002; Shek, 2005), in which social factors including family, school community and peer influence, have been the main research focus, some psychological factors such as self-concept and values have also been examined. However, Hong Kong research has been less focused on investigating the correlations between self-esteem and self-efficacy and the deviant behaviour of young people. This study aims to use a large sample of secondary school students to explore these correlates. In this study, perceived self-efficacy is defined as people's beliefs about their capabilities to produce designated levels of performance that exercise influence over events that affect their lives. Self-efficacy beliefs determine how people feel, think, motivate themselves and behave (Bandura, 1994). Self-esteem refers to general feelings of self-worth or self-value.

\section{Methodology}

\section{Sample}

Ten secondary schools were chosen by means of a multi-stage random sampling method. Eight were comprehensive schools and the remaining two were vocational schools. One class was randomly selected from each form in each school. A total of 1432 valid questionnaires were received. Eighty seven percent of the students were aged between 11 and 18 years $($ Mean $=16.14 ; \mathrm{SD}=$ 2.37). The majority of them were 18 years old $(20.5 \%), 17$ years old (17.4\%) and 16 years old (12.2\%); $7.9 \%$ were aged 12 years and below, 9.6\% were 13 years; $9.6 \%$ were 14 years, $8.4 \%$ were 15 years, and $9.3 \%$ were aged 19 years. Some of the older respondents were newly-arrived immigrants from Mainland China. Lacking a reasonable command of English, it was necessary for these students to start in lower forms, and as such, a small number of respondents (3\%) were aged 20 years or above. Over half $(58 \%)$ of the respondents were male and $42 \%$ were female, while $65 \%$ of respondents stated that they have no religion. Regarding educational levels, respondents were evenly spread across S1 to S7. Students in vocational schools comprised $13.7 \%$ of the total sample.

\section{Instrument/Measure}

The self-administered questionnaire, which took around 20 30 minutes to complete, consisted of a number of sections:

1) Demographics, including gender, age, educational background, school results and conduct etc;

2) Young People's Daily Behaviour Scale (18 items), (see Table 1). Respondents were asked to rate the weekly frequency of behaviours on a 4-point likert scale where " 1 " indicates "never" and "4" indicates "5 times or more". The items were adopted from similar research conducted by: Wong \& Cheng (2000), Baldry \& Farrington (2000), and Soldz \& Cui (2001);

3) Self-Esteem Scale (8 items) adopted from the Chinese Adolescent Self-Esteem Scales (CASES) (Cheng, 1998), designed for Hong Kong adolescents as a self-report scale measuring selfesteem, using 4-point Likert scale where " 1 " represents "strongly disagree" and "4" represents "strongly agree". CASES has obtained high reliability and validity in a number of studies (e.g. Cheng \& Watkins, 2000; Education and Manpower Bureau, 2003; Wong \& Watkins, 2001). The reliability in this study was relatively high at $\alpha=.84$.

4) Self-Efficacy Scale (10 items) adopted from a measure by Schwarzer et al. (1997), following the same 4-point Likert scale 
Table 1.

Respondents' daily activities.

\begin{tabular}{lcccc}
\hline & $\begin{array}{c}\text { Never, Seldom } \\
(\%)\end{array}$ & $\begin{array}{c}\text { Sometimes } \\
(\%)\end{array}$ & $\begin{array}{c}\text { Always } \\
(\%)\end{array}$ & Mean (SD) \\
\hline Watching television & 5.8 & 10.4 & 83.8 & $3.78(.56)$ \\
Doing homework, revision & 34.8 & 26.6 & 38.7 & $2.99(.94)$ \\
Surfing the internet, ICQ & 60.2 & 14.7 & 25.1 & $2.28(1.20)$ \\
Reading books, magazines & 61.3 & 22.6 & 16.2 & $2.36(.97)$ \\
Hanging out purposelessly & 75.1 & 13.1 & 11.8 & $2.07(.95)$ \\
Verbally attacking parents & 47.7 & 40.9 & 11.4 & $2.54(.82)$ \\
Smoking & 83.5 & 7.9 & 8.6 & $1.53(.96)$ \\
Playing sports with friends & 77.8 & 13.9 & 8.2 & $2.05(.85)$ \\
Window-shopping, watching movie & 76.8 & 15.4 & 7.8 & $2.23(.71)$ \\
Learning music, playing musical instruments & 88.3 & 5.1 & 6.6 & $1.54(.87)$ \\
Verbally attacking teachers & 70.9 & 23.6 & 5.5 & $2.09(.84)$ \\
Bullying, vandalism to seek excitement & 71.5 & 23.1 & 5.5 & $2.01(.88)$ \\
Joining extra-curricular activities & 83.7 & 10.9 & 5.5 & $1.83(.83)$ \\
Joining school/ local community activities & 86.3 & 9.5 & 4.3 & $1.81(.78)$ \\
Drinking alcohol & 78.7 & 17.2 & 4.1 & $1.70(.89)$ \\
Joining leisure courses & 93.2 & 4.3 & 2.4 & $1.46(.70)$ \\
Joining religious group activities & 96.1 & 2.0 & 1.9 & $1.32(.61)$ \\
Taking illegal drugs & 95.5 & 3.5 & 1.0 & $1.15(.51)$ \\
\hline
\end{tabular}

format as the self-esteem scale, the scale obtained a reliability score of .83 in the current study;

5) Rebelliousness Scale (5 items) adopted from Kaplan et al. (2001), again following the same 4-point Likert scale response system, it obtained an acceptable reliability of $\alpha=.66$;

6) Susceptibility to Negative Peer Influence Scale (6 items) constructed for local usage with modifications from the original version designed by Dalton et al. (1999) and Dielman et al. (1987), consisting of a 4-point scale, "1" = "certainly not" to "4" = "certainly". The reliability score for this part of measurement was $\alpha=.84$. Items from the self-esteem, self-efficacy, rebelliousness and susceptibility to negative peer influence scales were mixed randomly within the questionnaire in order to increase its internal validity.

\section{Results}

\section{Understanding Young People’ Daily Behaviour}

Table 1 shows the prevalence of respondents' daily activities, the most common daily behaviour of respondents was watching television, doing homework, and surfing the internet. Regarding delinquent behaviour, $24.9 \%$ of respondents sometimes or always hang out with friends, over $28 \%$ engaged in bullying and vandalism for excitement, $21.3 \%$ of respondents drank alcohol and $16.5 \%$ smoked. More than half $(52.3 \%)$ of the students admitted to sometimes or always verbally attacking their parents; while $29.1 \%$ of respondents sometimes or always verbally attacked their teachers.

The factor structure of the "Young People's Daily Behaviour Scale" was tested using Principal Components Analysis and Oblimin Rotation. Initial analysis revealed the presence of five components with eigenvalues greater than 1 , yielding a 5-factor solution accounting for $51.9 \%$ of the variance. All items had loadings above .3. These factors were labelled 1) deviant behaviour; 2) community active behaviour; 3) active learning behaviour; 4) semi-studious behaviour; and 5) aggressive behaviour (see Table 2).

In order to further comprehend the behavioural patterns of respondents, further exploratory factor analysis using different extraction criteria and rotation methods were attempted. Results revealed a 2 -factor solution accounting for $35 \%$ of the variance, and different extraction and rotation methods resulted in similar factor structure (see Table 3). The factors were labelled: 1) delinquent behaviour and 2) diligent behaviour. Delinquent behaviour included drinking alcohol, hanging out with friends, smoking, verbally attacking teachers, bully and vandalism to seek excitement, drug and substance abuse, verbally attacking parents, and not doing homework. Factor 2 represented more positive behaviour, such as engaging in constructive social activities. Results revealed that revising for homework was negatively correlated with delinquent behaviour (-.50), and positively correlated with diligent behaviour $(+.27)$, thus the more negative behaviour adolescents engaged in, the less likely they were to revise their homework. Reading books and magazines was positively correlated with diligent behaviour (.38). This pattern shows that there is a counteraction between engaging in constructive social activity and reading (Factor 2), and engaging in delinquent behaviour (Factor 1), suggesting that students who did not like studying were more likely to behave negatively.

We also analysed gender differences in respondents' daily behavioural patterns. Significant differences were found in respondents' daily behaviour; females were more likely to go window-shopping and watch movies $(p<.01)$, and were also more likely to verbally attack parents $(p<.01)$. Males were more likely to verbally attack teachers $(p<.01)$, bully and vandalise $(p<.05)$, engage in sports $(p<.01)$ and get involved in school or community activities $(p<.01)$ (see Table 4$)$. The noted gender differences are consistent with the different gender roles identified in previous paragraphs, indicating that male deviant behaviour tends to be mainly centred on violence and challenging authority; while female deviant behaviour is mainly associated with family and social relationships. 
Table 2.

Factor analyses of respondents' daily activities.

\begin{tabular}{|c|c|c|c|c|c|}
\hline & $\begin{array}{c}1 \\
\text { Deviant } \\
\text { behaviour }\end{array}$ & $\begin{array}{c}2 \\
\text { Community } \\
\text { active behaviour }\end{array}$ & $\begin{array}{c}3 \\
\text { Learned } \\
\text { behaviour }\end{array}$ & $\begin{array}{c}4 \\
\text { Semi-studious } \\
\text { behaviour }\end{array}$ & $\begin{array}{c}5 \\
\text { Aggressive } \\
\text { behaviour }\end{array}$ \\
\hline Smoking & .66 & & & & \\
\hline Hanging out purposelessly & .64 & & & & \\
\hline Drinking alcohol & .56 & & & & \\
\hline Taking illegal drugs & .55 & & & & \\
\hline Window-shopping, watching movie & .51 & & & & \\
\hline Doing homework, revision & -.65 & & & & \\
\hline Joining school/local community activities & & .79 & & & \\
\hline Joining extra-curricular activities & & .74 & & & \\
\hline Playing sports with friends & & .72 & & & \\
\hline Learning music, playing music instruments & & & .64 & & \\
\hline Joining religious group activities & & & .55 & & \\
\hline Watching television & & & -.53 & & \\
\hline Joining leisure courses & & & .52 & & \\
\hline Surfing internet, ICQ & & & & .73 & \\
\hline Reading books, magazines & & & & .72 & \\
\hline Verbally attacking parents & & & & & .72 \\
\hline Bullying, vandalism to seek excitement & & & & & .70 \\
\hline Verbally attacking teachers & & & & & .68 \\
\hline
\end{tabular}

Extraction method: principal component analysis, $51.9 \%$ variance explained, oblimin rotation, loadings smaller than .25 were not displayed.

Table 3.

Factor analyses of adolescents' delinquent behaviour (Factor 1) and diligent behaviour (Factor 2).

\begin{tabular}{lcc}
\hline & $\begin{array}{c}1 \\
\text { Delinquent } \\
\text { Behaviour }\end{array}$ & $\begin{array}{c}\text { Diligent } \\
\text { Behaviour }\end{array}$ \\
\hline Drinking alcohol & .68 & \\
Hanging out purposelessly & .67 & .65 \\
Smoking & .61 & \\
Verbally attacking teachers & .59 & \\
Bullying, vandalism to seek excitements & .53 & \\
Taking illegal drugs & .48 & .75 \\
Window-shopping, watching movie & .41 & .74 \\
Verbally attacking parents & .39 & .61 \\
Surfing internet, ICQ & -.50 & .55 \\
Doing homework, revision & & .42 \\
Joining school/local community activities & & .45 \\
Joining extra-curricular activities & & .38 \\
Joining leisure courses & & \\
Playing sports with friends & & \\
Learning music, playing music instruments & & \\
Joining religious group activities & & \\
Reading books, magazines & & \\
\hline Etrat & & \\
\hline
\end{tabular}

Extraction method: principal component analysis, varimax rotation. 
Table 4.

Gender differences in the prevalence of daily activities.

\begin{tabular}{|c|c|c|c|c|c|c|c|}
\hline & \multicolumn{2}{|c|}{ Male } & \multicolumn{2}{|c|}{ Female } & \multirow[b]{2}{*}{ t-test } & \multirow[b]{2}{*}{ Cohen's d } & \multirow[b]{2}{*}{$\mathrm{r} \gamma \lambda$} \\
\hline & Mean & $\mathrm{SD}$ & Mean & SD & & & \\
\hline Watching television & 3.79 & $(.55)$ & 3.75 & $(.57)$ & 1.40 & .075 & .037 \\
\hline Doing homework, revision & 2.98 & $(.99)$ & 3.01 & $(.86)$ & -.57 & -.030 & .015 \\
\hline Verbally attacking parents & 2.47 & $(.80)$ & 2.64 & $(.83)$ & $-3.93 * *$ & -.209 & .104 \\
\hline Playing sports with friends & 2.26 & $(.87)$ & 1.75 & $(.73)$ & $11.65^{* *}$ & .087 & .043 \\
\hline Surfing internet, ICQ & 2.23 & $(1.24)$ & 2.35 & (1.14) & -1.83 & -.245 & .122 \\
\hline Verbally attacking teachers & 2.19 & $(.86)$ & 1.95 & $(.78)$ & $5.54 * *$ & .000 & .000 \\
\hline Window shopping, watching movies & 2.15 & $(.72)$ & 2.32 & $(.68)$ & $-4.61 * *$ & .620 & .296 \\
\hline Bullying, vandalism, to seek excitement & 2.05 & $(.89)$ & 1.96 & $(.87)$ & $2.05^{*}$ & .100 & .050 \\
\hline Joining school/local community activities & 1.89 & $(.79)$ & 1.69 & $(.73)$ & $4.77 * *$ & .254 & .126 \\
\hline Joining extra-curricular activities & 1.87 & $(.81)$ & 1.78 & $(.86)$ & 1.88 & -.070 & .035 \\
\hline Drinking alcohol & 1.73 & $(.92)$ & 1.66 & $(.86)$ & 1.36 & -.081 & .040 \\
\hline Smoking & 1.54 & $(.99)$ & 1.51 & $(.92)$ & .69 & .295 & .146 \\
\hline Learning music, playing musical instruments & 1.50 & $(.89)$ & 1.57 & $(.83)$ & -1.48 & .109 & .054 \\
\hline Joining leisure courses & 1.44 & $(.70)$ & 1.49 & (.66) & -1.32 & .072 & .036 \\
\hline Joining religious group activities & 1.30 & $(.62)$ & 1.35 & $(.60)$ & -1.51 & .037 & .019 \\
\hline Taking illegal drugs & 1.14 & $(.51)$ & 1.16 & $(.50)$ & -.45 & -.024 & .012 \\
\hline
\end{tabular}

$* p<.05, * * p<.01$, d.f. $=1388-1416$ due to missing values.

\section{Correlations between Self-Concepts, Rebelliousness, Susceptibility to Negative Peer Influence and Deviant Behaviour}

Correlation analyses were conducted on the relationship between self-esteem, self-efficacy, rebelliousness, susceptibility to negative peer influence and deviant behaviour (see Table 5). Significant positive correlations were found between "deviant behaviour" and "susceptibility to negative peer influence", and between "deviant behaviour" and "rebelliousness", with correlations of +.69 and $+.88(p<.01)$. These findings suggest that the more "deviant behaviour" respondents engaged in, the more rebellious they became, and the more susceptible they were to negative peer influence. A relatively weak and negative correlation was found between "self-esteem" and "deviant behaviour". No correlations were found between "deviant behaviour" and "self-efficacy" ( $\mathrm{r}=0, p=.98)$, and between "self-efficacy" and "rebelliousness" $(\mathrm{r}=0, p=.90)$. Negative correlations were found between "deviant behaviour", "susceptibility to negative peer influence" and "self-esteem" (-.13 and $-.16, p<.001)$, demonstrating that respondents with lower self-esteem were more susceptible to negative peer influences and were more likely to engage in deviant behaviour. However, such correlations were weak, which suggest their relationship could be more complex.

Results indicate that Hong Kong respondents' deviant behaviour is generally positively correlated to "rebelliousness" and "susceptibility to negative peer influence", though the relationship between "deviant behaviour" and "self-concepts" was not direct. Using ANOVA, we analysed the effects of deviant behaviour on self-esteem, self-efficacy, rebelliousness, and suscep- tibility to negative peer influence. The results were consistent with but provided more information than those obtained from the correlation analyses. ANOVA results indicated that all deviant behaviours had significant effects with "rebelliousness" and "susceptibility to negative peer influence". Furthermore, these differences followed the linear trend with deviant behaviours (all linear contrasts $p<.01$ ), suggesting that the more frequent the deviant behaviour, the higher the rebelliousness, and the more susceptible to negative peer influence. However, not all types of deviant behaviours had significant effects on respondents' self-esteem or self-efficacy. Only "bullying/vandalism", "verbally/physically attacking parents", "lack of motivation to study", and "verbally/physically attacking teachers" had significant effects with self-esteem and/or self-efficacy ( $p<.01$; differences in self-esteem scores were only significant in the first three items) (see Table 6).

It is interesting to note that the relationship between "bullying/vandalism" with self-esteem and with self-efficacy followed a non-linear but U-shape trend as indicated by the polynomials contrast tests $(p<.001)$. This demonstrates that students' selfesteem and self-efficacy decreased when they engaged in "bullying or vandalism", and stayed at the lowest level when they occasionally engaged in these behaviours. However, their selfconcept gradually increased when they engaged in this behaveiour more regularly. The self-efficacy levels of frequent delinquents were even higher than those of non-delinquents. Moreover, although the relationship between "lack of motivation for studying", "verbally or physically attacking parents", "verbally or physically attacking teachers" and "self-esteem" and/or "selfefficacy" follow a linear fashion, they were in different directions. 
Table 5.

Correlations between deviant behaviour, self-esteem, self-efficacy and susceptibility to negative peer influence.

\begin{tabular}{|c|c|c|c|c|c|}
\hline & Deviant behaviour & Self-esteem & Self-efficacy & Rebelliousness & $\begin{array}{c}\text { Susceptibility to } \\
\text { negative peer influence }\end{array}$ \\
\hline Deviant behaviour & 1.0 & $-.13 * *$ & 0 & $.88^{* *}$ & $.69^{* *}$ \\
\hline Self-esteem & & 1.0 & $.63^{* *}$ & $-.15^{* *}$ & $-.16^{* *}$ \\
\hline Self-efficacy & & & 1.0 & 0 & $-.08 * *$ \\
\hline Rebelliousness & & & & 1.0 & $.59 * *$ \\
\hline Susceptibility to negative peer influence & & & & & 1.0 \\
\hline
\end{tabular}

$* * p<.01, \mathrm{~N}=1340$ to 1419 .

Table 6.

Effects of negative behaviours on self-efficacy and self-esteem.

\begin{tabular}{|c|c|c|c|c|c|c|c|c|}
\hline \multirow{2}{*}{ Behaviour } & \multirow{2}{*}{ Self-concepts } & \multirow{2}{*}{ Never } & \multirow{2}{*}{ A little } & \multirow{2}{*}{ Sometimes } & \multirow{2}{*}{ Often } & \multirow{2}{*}{$\begin{array}{l}\text { Overall } \\
\text { F-tests }\end{array}$} & \multicolumn{2}{|c|}{ Polynomial contrasts } \\
\hline & & & & & & & linear & quadratic \\
\hline \multirow{2}{*}{ Verbally/physically attacking parents } & Self-esteem & 22.86 & 22.69 & 21.49 & 20.52 & $18.00^{* * *}$ & $33.99 * * *$ & $2.39 \mathrm{~ns}$ \\
\hline & Self-efficacy & 27.40 & 26.82 & 26.47 & 25.96 & $3.65^{* *}$ & $3.65^{* *}$ & $.11 \mathrm{~ns}$ \\
\hline \multirow{2}{*}{ Verbally/physically attacking teachers } & Self-esteem & 22.30 & 22.01 & 21.60 & 21.52 & $2.00 \mathrm{~ns}$ & $3.06 \mathrm{~ns}$ & $.12 \mathrm{~ns}$ \\
\hline & Self-efficacy & 26.58 & 26.27 & 27.15 & 27.70 & $5.06^{* *}$ & $6.99 * *$ & $2.07 \mathrm{~ns}$ \\
\hline \multirow{2}{*}{ Bullying, vandalism to seek excitements } & Self-esteem & 22.76 & 21.87 & 20.93 & 22.18 & $13.42 * * *$ & $3.13 \mathrm{~ns}$ & $14.01 * * *$ \\
\hline & Self-efficacy & 26.84 & 26.36 & 26.40 & 28.18 & $5.04 * *$ & $6.74 * *$ & $14.71^{* * *}$ \\
\hline \multirow{2}{*}{ Doing homework, revision } & Self-esteem & 20.87 & 21.42 & 21.99 & 22.53 & $7.87^{* * *}$ & $12.53 * * *$ & $0 \mathrm{~ns}$ \\
\hline & Self-efficacy & 25.61 & 26.26 & 26.68 & 27.02 & $4.14 * *$ & $8.24^{* *}$ & $.25 \mathrm{~ns}$ \\
\hline
\end{tabular}

$* * p<.01, * * * p<.001 ;$ d.f. $=3,1392$ to 1403 .

The relationships indicate that the more respondents attacked their parents and the less motivation they had in studying, the lower their self-esteem and self-efficacy. However, the effect of attacking teachers was quite different from attacking parents or lacking motivation in studying. While there was no significant relationship between attacking teachers and respondents' selfesteem, it was found that students who attacked teachers more often also had higher self-efficacy (see Table 6). This is dissimilar to the effect of attacking parents, which was related to lower self-esteem and lower self-efficacy, demonstrating that students with higher self-esteem and higher self-efficacy would be less prone to attack their parents and would have higher motivation in studying, but might attack teachers at times.

\section{Conclusion}

A significant body of literature researching the role of deviant peer influence on delinquent behaviour in young people lends support to the hypothesis that associating with deviant peers significantly increases the likelihood of individual delinquency for some youth (Gifford-Smith et al., 2005). The present study discovered that the more rebellious and susceptible to peer influence adolescents were, the more severe the types of deviant behaveiour they engaged in. The results of the current study were consistent with previous research where delinquent association has been observed to be an important factor for the rise in severity of adolescent deviant behaviour (Lacourse et al., 2003; Vitaro et al., 2005). If adolescents fail to gain social acceptance through normal living experiences, an impaired self-image may develop. If this is combined with relatively low self-esteem and self-discipline (high rebelliousness) and high susceptibility to peer influence (low resilience), adolescents may naturally try to selfactualize and gain acceptance in other social groups (illegitimate, unruly ones) through engaging in deviant behaviour (Wentzel, 1994; Sung \& Thornberry, 1998; Allen et al., 2005).

These findings are consistent with a developmental process in which reward dominant youth are more likely to associate deviant behaviour with the rewards provided by deviant peers than to associate this behaviour with punishments provided by adults (Goodnight et al., 2006). However, it is important to note that not all types of deviant behaviour have a similar linear relationship with self-concept. Weak direct relationships were found between deviant behaviour and self-efficacy and self-esteem, however, deviant behaviour was associated with the desire to gain acceptance from peers. Therefore, the deeper the desire, the more severe the types of deviant behaviour young people engaged in.

Differences were found in the roles of authority between parents and teachers. Since it is easier for delinquents to be noticed by their peers through openly challenging their teacher's authority, delinquents' self-esteem and self-efficacy will gradually be enhanced (self-enhancing effect) once they are frequently engaged in unruly behaviour in an open manner, i.e. the more they 
verbally attack their teachers, the higher their self-esteem and self-efficacy will become.

Gender differences were found in respondents' deviant behaviour whereby male respondents were more likely to verbally attack teachers, bully, and vandalise. This supports previous findings demonstrating the negative impact of poor school relations on male delinquency (Lau \& Leung, 1992). Female respondents were found to be more likely to verbally attack parents, as opposed to teachers. As adolescents mostly will not have the opportunity to witness peers challenging their parents in the home, their self-esteem will remain relatively low as their self-esteem and self-efficacy are not enhanced as a result. The above findings are consistent with Kaplan's Self-Enhancement Model (1975) and other relevant research (e.g. Wentzel, 1994; Mason, 2001; Donnellan et al., 2005; Forney et al., 2005).

Associating with delinquent peers was related to increased rates of delinquency among Hong Kong secondary school students. However, what is difficult to define is whether delinquent adolescents affiliate with delinquent friends, or whether delinquent friends produces delinquent adolescents (Fergusson et al., 2007). Our findings were consistent with those of Bartlett and associates (2006), in that self-esteem was found to be a protecttive factor against the risk of deviant behaviour. Through factor analysis, we found different behavioural patterns from two groups of students engaging in either diligent social activities or those of a deviant nature. Students were less likely to become part of a delinquent group if they engaged themselves more in diligent social activities. Self-efficacy and self-esteem will also be enhanced if the diligent social effect can be strengthened among students through engaging in such activities.

Deviant behaviour can be viewed as another expression of prosocial behaviour within the delinquent network where more peer acceptance is gained through committing more severe acts of deviance (at least from the delinquents' perspective). The enhancement of young people's self-esteem (gaining peer attention) through engaging in deviant behaviour is more significant and is an important factor in their susceptibility to peer influence and rebelliousness. This mechanism acts as a vicious cycle for delinquents. Initially when deviant behaviour emerges, delinquents' self-esteem is relatively low and there is a strong desire to be accepted by peers, once youths have built their reputation within their delinquent peer group, they will gradually become role-models for junior delinquents and their behaviour will no longer be affected by peer pressure. Delinquents may have a relatively low self-esteem prior to, or in the initial stages of, the emergence of deviant behaviour, but self-esteem will gradually be enhanced once the behaviour has gained peer support.

Youth delinquency is a problem with multiple causes and effects, and the present study found that self esteem is a crucial factor. Hong Kong has attempted to help delinquent students through a "one school-one social worker" system. Before developing any effective intervention strategies, it is essential to understand the aforementioned crucial factor associated with school delinquency in Hong Kong. Students should be provided with the opportunity to participate in co-curricular or after school activities, so as to release their stress and anxiety, and channel their rebellious behaviour in constructive ways. Active participation in activities could help to develop their potential and enhance self-confidence and self-esteem, thus serving as a protective factor of delinquency. Since students often turn to their peers, including deviant ones, for support during times of stress and anxiety, they should be coached on how to resist undesirable peer pressure through proper social skills; helping them to rebuild their social circles is a necessary strategy.
To conclude, to change the deviant identity of school delinquents is central to social work for young people. Without a new identity, they would feel easy to mingle with their former deviant peers. Social work in school should prepare the delinquents for the new roles they are to play after any intervention programmes. However, preoccupation with their previous deviant identity is a hurdle for positive change; they may seek to resolve the crises and frustrations they encountered by deviant means. To rebuild their identity, they need to look for someone or something that they have faith in, no matter these are vocational, social, humanitarian and political cause; or they have to experience success or achieve social status through conventional means, such as the Hong Kong Award for Young People, sports talent programme, volunteer services, mentoring, and role modelling. The identity-rebuilding process would gradually strengthen their self-image and self-efficacy, remove their deviant self-concept, and prevent them from going astray.

\section{References}

Allen, J. P., Porter, M. R., McFarland, F. C., Marsh, P., \& McElhaney, K. B. (2005). The two faces of adolescents' success with peers: Adolescent popularity, social adaptation and deviant behaviour. Child Development, 76, 747-760. doi:10.1111/j.1467-8624.2005.00875.x

Baldry, A. C., \& Farrington, D. P. (2000). Bullies and delinquents: Personal characteristics and parental styles. Journal of Community and Applied Social Psychology, 10, 17-31. doi:10.1002/(SICI)1099-1298(200001/02)10:1<17::AID-CASP526> 3.0.CO;2-M

Bartlett, R., Holditch-Davis, D., Belyea, M., Halpern, C. T., \& Beeber, L. (2006). Risk and protection in the development of problem behaviors in adolescents. Research in Nursing \& Health, 29, 607-621. doi:10.1002/nur.20163

Becker, B. E., \& Luthar, S. S. (2007). Peer-perceived admiration and social preference: Contextual correlates of positive peer regard among suburban and urban adolescents. Journal of Research on Adolescence, 17, 117-144. doi:10.1111/j.1532-7795.2007.00514.x

Carroll, A., Houghton, S., Hattie, J., \& Durkin, K. (1999). Adolescent reputation enhancement: Differentiating delinquent and non-delinquent youths. Journal of Child Psychology \& Psychiatry \& Allied Disciplines, 40, 593-606. doi:10.1111/1469-7610.00476

Chen X., Chang, L., He, Y., \& Liu, H. (2005). The peer group as a context: Moderating effects on relations between maternal parenting and social and school adjustment in Chinese children. Child Development, 76, 417-434. doi:10.1111/j.1467-8624.2005.00854.x

Cheng, C. H. K. (1998). An indigenous instrument for measuring the self-esteem of Hong Kong Chinese adolescents. Paper Presented in the International Conference on the Application of Psychology to the Quality of Learning and Teaching, Hong Kong: University of Hong Kong.

Cheng, C. H. K., \& Watkins, D. (2000). Age and gender invariance of self-concept factor structure: An investigation of a newly developed Chinese self-concept instrument. International Journal of Psychology, 35, 186-193. doi:10.1080/00207590050171120

Cheung, Y. W. (1993). Predicting adolescent behaviour in Hong Kong: A comparison of media, family, school and peer variables. Hong Kong: Institute of Asia-Pacific Studies, Chinese University of Hong Kong.

Cheung, Y. W., \& Ng, A. (1988). Social factors in adolescent deviant behaviour in Hong Kong: An integrated theory approach. International Journal of Comparative \& Applied Criminal Justice, 12, 27-45.

Claes, M., Lacourse, E., Ercolani, A. P., Pierro, A., Leone, L., \& Presaghi, F. (2005). Parenting, peer orientation, drug use, and antisocial behaviour in late adolescence: A cross-national study. Journal of Youth \& Adolescence, 34, 401-411. doi:10.1007/s10964-005-7258-8

Dalton, M., Sargent, J., Beach, M., Bernhardt, A., \& Stevens, M. (1999). Positive and negative outcome expectations of smoking: Implications 
for prevention. Preventive Medicine, 29, 460-465. doi:10.1006/pmed.1999.0582

Dielman, T., Campanelli, P., Shope, J., \& Butchart, A. (1987). Susceptibility to peer pressure, self-esteem, and health locus of control as correlates of adolescent substance abuse. Health Education Quarterly, 14, 207-221. doi:10.1177/109019818701400207

Donnellan, M. B., Trzesniewski, K. H., Robins, R. W., Moffitt, T. E., \& Caspi, A. (2005). Low self-esteem is related to aggression, anti-social behavior, and delinquency. Psychological Science, 16, 328-335. doi:10.1111/j.0956-7976.2005.01535.x

DuBois, D. L., \& Silverthorn, N. (2004). Do deviant peer associations mediate the contributions of self-esteem to problem behaviour during early adolescence? A 2-year longitudinal study. Journal of Clinical Child \& Adolescent Psychology, 33, 382-388. doi:10.1207/s15374424jecp3302_20

Duckworth, A. L., \& Seligman, M. E. P. (2005). Self-discipline outdoes IQ in predicting academic performance of adolescents. Psychological Science, 16, 939-944. doi:10.1111/j.1467-9280.2005.01641.x

Education and Manpower Bureau (2003). Assessment program for affective and social outcomes (secondary schools). Hong Kong: The Education and Manpower Bureau, Hong Kong SAR Government.

Fergusson, D. M., Vitaro, F., Wanner, B., \& Brendgen, M. (2007). Protective and compensatory factors mitigating the influence of deviant friends on delinquent behaviors during early adolescence. Journal of Adolescence, 30, 33-50. doi:10.1016/i.adolescence.2005.05.007

Fergusson, D. M., Wanner, B., Vitaro, F., Horwood, L. J., \& SwainCampbell, N. R. (2003). Deviant peer affiliations and depression: Confounding or causation? Journal of Abnormal Child Psychology, 31, 605-618. doi:10.1023/A:1026258106540

Forney, W. S., Forney, J. C., \& Crutsinger, C. (2005). Gender, delinquent status and social acceptance as predictors of the global self-esteem of teens. Family \& Consumer Sciences Research Journal, 33, 208-219. doi:10.1177/1077727X04272364

Gifford-Smith, M., Dodge, K. A., Dishion, T. J., \& McCord, J. (2005). Peer influence in children and adolescents: Crossing the bridge from developmental to intervention science. Journal of Abnormal Child Psychology, 33, 255-265. doi:10.1007/s10802-005-3563-7

Goodnight, J. A., Bates, J. E., Newman, J. P., Dodge, K. A., \& Pettit, G. S. (2006). The interactive influence of friend deviance and reward dominance on the development of externalizing behaviour during middle adolescence. Journal of Abnormal Child Psychology, 34, 573-583. doi:10.1007/s10802-006-9036-9

Kaplan, H. B. (1975). Self-attitudes and deviant behavior. Pacific Palisades, CA: Goodyear.

Kaplan, H. B., \& Lin, C. H. (2000). Deviant identity as a moderator of the relation between negative self-feelings and deviant behaviour. The Journal of Early Adolescence, 20, 150-177. doi: $10.1177 / 0272431600020002003$

Kaplan, H. B., \& Lin, C. H. (2005). Deviant identity, negative self-feelings, and decreases in deviant behaviour: The moderating influence of conventional social bonding. Psychology, Crime \& Law, 11, 289-303. doi:10.1080/10683160412331294817

Kaplan, C., Napoles-Springer, A., Stewart, S., \& Perez-Stable, E. (2001). Smoking acquisition among adolescents and young Latinas: The role of socio environmental and personal factors. Addictive Behaviors, 26, 531-550. doi:10.1016/S0306-4603(00)00143-X

Karatzias, A., Chouliara, Z., Power, K., \& Swanson, V. (2006). Predicting general well-being from self-esteem and affectivity: An exploratory study with Scottish adolescents. Quality of Life Research, 15, 1143-1151. doi:10.1007/s11136-006-0064-2

Katja, R., Paivi, A. K., Marja-Terttu, T., \& Pekka, L. (2002). Relationships among adolescents' subjective well-being, health behaviour, and school satisfaction. The Journal of School Health, 72, 243-249. doi:10.1111/j.1746-1561.2002.tb07337.x

Kim, H-S., \& Kim, H-S. (2005). Gender differences in delinquent behavior among Korean adolescents. Child Psychiatry \& Human Development, 35, 325-345. doi:10.1007/s10578-005-2691-1

Lacourse, E., Nagin, D., Tremblay, R. E., Vitaro, F., \& Claes, M. (2003). Developmental trajectories of boys' delinquent group membership and facilitation of violent behaviours during adolescence. Development \& Psychopathology, 15, 183-197. doi: $10.1017 / \mathrm{S} 0954579403000105$

Lau, S., \& Leung, K. (1992). Relations with parents and school and Chinese adolescents' self-concept, delinquency and academic performance. British Journal of Educational Psychology, 62, 193-202. doi:10.1111/j.2044-8279.1992.tb01013.x

Level, L. D., \& Chamberlain, P. (2005). Association with delinquent peers: Intervention effects for youth in the juvenile justice system. Journal of Abnormal Child Psychology, 33, 339-347. doi: 10.1007/s10802-005-3571-7

Levy, K. S. C. (1997). Multifactorial self-concept and delinquency in Australian adolescents. Journal of Social Psychology, 137, 277-283. doi: $10.1080 / 00224549709595439$

Levy, K. S. C. (1997). The contribution of self-concept in the etiology of adolescent delinquency. Adolescence, 32, 671-686.

Li, J. C. M., \& Lo, T. W. (2006). Youth gang violence and neutralization technique. Journal of Youth Studies, 9, 142-150.

Lo, T. W. (1984). Gang Dynamics. Hong Kong: Caritas.

Mason, A. (2001). Self-esteem and delinquency revisited (again): A test of Kaplan's self-derogation theory of delinquency using latent growth curve modelling. Journal of Youth and Adolescence, 30, 83-102. doi:10.1023/A:1005276905961

Rigby, K., \& Cox, I. (1996). The contribution of bullying at school and low self-esteem to acts of delinquency among Australian teenagers. Personality \& Individual Differences, 21, 609-612. doi:10.1016/0191-8869(96)00105-5

Schwartz, D, Gorman, A. H., Nakamoto, J., \& McKay, T. (2006). Popularity, social acceptance and aggression in adolescent peer groups: Links with academic performance and school attendance. Developmental Psychology, 42, 1116-1127.

doi:10.1037/0012-1649.42.6.1116

Schwarzer, R., Bäßler, J., Kwiatek, P., Schröder, K., \& Zhang, J. (1997). The assessment of optimistic self-beliefs: Comparison of the German, Spanish, and Chinese versions of the general self-efficacy scale. $A p$ plied Psychology: An International Review, 46, 68-88.

Shek, D. T. L. (2005). Paternal and maternal influences on the psychological well-being, substance abuse, and delinquency of Chinese adolescents experiencing economic disadvantage. Journal of Clinical Psychology, 61, 219-234. doi:10.1002/jclp.20057

Soldz, S., \& Cui, X. (2001). A risk factor index predicting adolescent cigarette smoking: A 7-year longitudinal study. Psychology of Addictive Behaviors, 15, 33-41. doi:10.1037/0893-164X.15.1.33

Sung, J. J., \& Thornberry, T. P. (1998). Self-esteem, delinquent peers, and delinquency: A test of the self-enhancement thesis. American Sociological Review, 63, 586-598.

Tabassam, W., \& Grainger, J. (2002). Self-concept, attributional style and self-efficacy beliefs of students with learning disabilities. Learning Disability Quarterly, 25, 141-151. doi: $10.2307 / 1511280$

van Lier, P. A. C., Vitaro, F., Wanner, B., Vuijk, P., \& Crijnen, A. A. M. (2005). Gender differences in developmental links among antisocial behaviour, friends' antisocial behaviour, and peer rejection in childhood: Results from two cultures. Child Development, 76, 841-855. doi:10.1111/j.1467-8624.2005.00881.x

Vitaro, F., Brendgen, M., \& Wanner, B. (2005). Patterns of affiliation with delinquent friends during late childhood and early adolescence: Correlates and consequences. Social Psychiatry, 14, 82-108.

Wentzel, K. R. (1994). Relations of social goal pursuit to social acceptance, classroom behaviour, and perceived social support. Journal of Educational Psychology, 86, 173-182.

doi: $10.1037 / 0022-0663.86 .2 .173$

Wentzel, K. R. (2004). Understanding classroom competence: The role of social-motivational and self-processes. Advances in Child Development \& Behavior, 32, 213-241. doi:10.1016/S0065-2407(04)80008-9

Wong, D. S. W., \& Cheng, C. (2000). Religious bonds, values and minor delinquency among young people in Hong Kong. Journal of Youth Studies, 3, 142-151.

Wong, J. P. S., \& Leung, A. Y. M. (2002). Health education and lifestyle in Hong Kong youth people. Journal of Youth Studies, 5, 186-202.

Wong, S. W., \& Watkins, D. (2001). Self-esteem and ability grouping: A Hong Kong investigation of the Big Fish Little Pond Effect. Educational Psychology, 21, 79-87. doi:10.1080/01443410123082 